\title{
Influence of occupation and living habits on semen quality in men (scrotal insulation and semen quality)
}

\author{
Joop S.E. Laven ${ }^{1}$, Michiel J. Haverkorn ${ }^{2}$ and Rob S.G.M. Bots ${ }^{3}$ \\ ${ }^{I}$ Department of Anatomy, School of Veterinary Medicine, State University Utrecht, Utrecht, \\ ${ }^{2}$ Laboratory for Medical Microbiology, Stichting de PAMM, Eindhoven \\ and ${ }^{3}$ Department for Gynecology and Obstetrics, St. Elisabeth Hospital, Tilburg. The Netherlands
}

Accepted for publication 13 April 1988

\section{Summary}

Fifty-six males from infertile couples were categorised into two different groups and their semen quality examined. Patients in which there was no evidence of interference with normal testicular thermoregulation either during the day or the night were classified as 'cool workers' and 'cool sleepers' (Group I, $n=26$ ). In the other group (II), 'warm workers'/'warm sleepers' $(\mathrm{n}=30)$, there was evidence for scrotal insulation. The number of good moving spermatozoa per ejaculate as well as this number per $\mathrm{ml}$ was greater in 'cool workers' /cool sleepers' than in 'warm workers' / warm sleepers' ( $\mathrm{p}<0.001$ ). These results emphasize the need for comprehensive patient history when evaluating infertility problems. Similarly, living habits may play a role in human male infertility and treatment.

Scrotal insulation; Semen; Man

\section{Introduction}

The temperature at which normal spermatogenesis in most mammals occurs is $3-4^{\circ} \mathrm{C}$ below normal intra-abdominal temperature [1-3]. These mammals possess mechanisms to regulate intratesticular temperature, the most important of which are the scrotum with its wall adaptation and the counter-current heat-exchange mechanism [4-7]. Elevated temperatures, either from a febrile state or local elevations, can affect the seminiferous tubules, impairing spermatogenesis and causing abnormal sperm morphology $[2,3,8]$. Conversely, it is thought that Leydig cells are not

Correspondence: J.S.E. Laven, Department of Anatomy, School of Veterinary Medicine, State University Utrecht, Yalelaan 1, P.O. Box 80.157, 3508 TD Utrecht, The Netherlands. 
temperature sensitive. However, recent reports indicate that testosterone produced by Leydig cells from heated testes (at $43^{\circ} \mathrm{C}$ for $30 \mathrm{~min}$ ) may not be secreted as effectively as in normal testis $[9,10]$. Scrotal insulation preventing adequate heat exchange, can result in an elevated testicular temperature resulting in a disruption of normal spermatogenesis [5].

The insulating effects of clothing in men might cause such an increase in the 'deep scrotal' temperature [11], while repeated increases in body temperature might also influence spermatogenesis $[3,8]$. Besides the insulating effect, clothing may raise testicular temperature through prolonged contact with adjacent warm body tissues (i.e., thighs, lower abdomen).

In this paper a study of the influence of occupation and living habits on semen quality in men is presented.

\section{Materials and methods}

\section{Patients}

At the first visit to our infertility clinic we had a comprehensive interview with the males of infertile couples. During the interview the attention was focussed, among other things, on their occupation and living habits. Attention was given to a sitting versus a non-sitting occupation, to sleeping with or without underwear, and to regular use of electric blankets, down filled quilts, saunas and hot baths $[8,11]$.

Patients with any type of disease 3 months prior to the interview and users of drugs known to interfere with spermatogenesis were excluded from the study. Users of excessive amounts of alcohol ( $\geq 5$ glasses/day) as well as heavy smokers ( $\geq 25$ cigarettes/day) were also excluded [12,13].

Following a general physical examination, in the patients suspected of having a varicocele, further screening was done using Doppler flowmetry and scrotal thermography [14]. The 16 patients diagnosed to have varicocele were excluded from the study. Serum levels of LH, FSH and testosterone were measured in all patients, and those showing abnormal levels for any of these hormones were not included in the analysis.

Based on occupation and sleeping habits the patients were categorized into two groups. Patients in which there was no evidence for interference with normal heat dissipation during the day nor during the night were classified in group I, the 'cool workers' and 'cool sleepers'. The second group consisted of patients in which during the day and night there was evidence for scrotal insulation, 'warm workers' and 'warm sleepers'; in general, those patients that were sitting during an average working day for 6 hours or more and were sleeping with underwear on ( $\mathrm{Y}$-fronts) or used electric blankets or down filled quilts.

\section{Semen analysis}

Following physical examination, two semen samples were collected by masturbation, at weekly or biweekly intervals, after a 3 day period of abstinence. At least two semen samples per patient were analysed by standard procedures [15]. Sperm motility was assessed quantitatively as well as qualitatively within 2 hours of collection. Semen volume, sperm cell concentration, total sperm number and cell 
morphology was determined. The quality of sperm motility was classified as no, poor, impaired, good or excellent movement [15]. It was found that spermatozoa having abnormal morphology have either no or sluggish movement [16], therefore the number of good moving spermatozoa per $\mathrm{ml}$ and the total volume of ejaculate were considered the most uscful parameters.

\section{Statistical evaluation}

Group differences in the parameters were compared using the Wilcoxon-Ranksum test. Differences in age distribution between the two groups were analysed using the Students $t$ test.

\section{Results}

\section{Patients}

Of the 56 men included in this study, $54 \%$ were found to have a sitting occupation and slept with underwear on.

Although the lifestyle of several patients included the use of electric blankets, down filled quilts, sauna and hot baths their incidence was too low for further analysis. Differences in age distribution between the two groups are not statistically significant ( $\mathrm{p}>0.1)$. The mean age in group I was 29.4 years (3.58 (SD)) and ages ranged from 21 up to 35 years. In group II the mean age was 29.9 years (3.72 (SD)) with a range from 21 up to 41 years.

\section{Semen analysis}

Figs. 1 and 2 are graphical representations of the distribution of good moving spermatozoa in the two groups. Since the distribution was not homogeneous they are presented on a semi-logarithmic scale. Mean values indicate differences between the two groups. The total number of second samples is lower than the total number

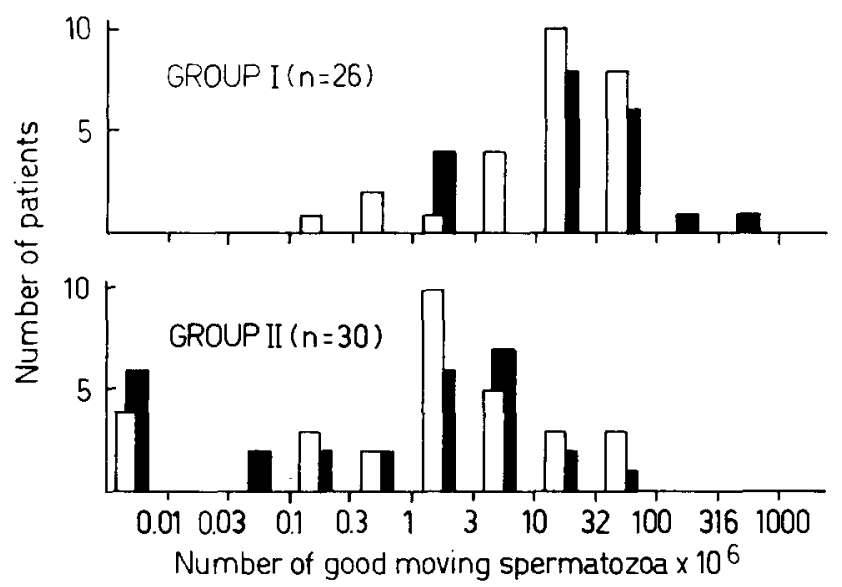

Fig. 1. Graphical representation of the number of good moving spermatozoa per $\mathrm{ml}$ in each of the groups (open bars $=$ first sample, closed bars $=$ second sample) . 


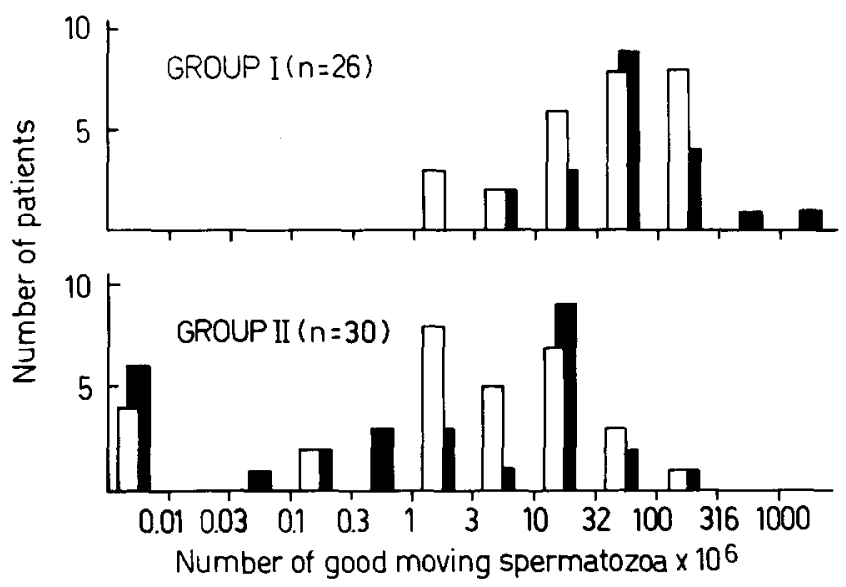

Fig. 2. Graphical representation of the number of good moving spermatozoa per ejaculate in each of the groups (open bars $=$ first sample, closed bars $=$ second sample).

of first samples, as eight men presented only one semen sample. Differences between the first and second sample in each group were not significant.

Patients in group I consistently exhibited a greater sperm motility than group II. The number of good moving spermatozoa $/ \mathrm{ml}$ in the first as well as the second sample were significantly $(\mathrm{p}<0.001)$ higher in group I than in group II. The same significant difference was found in the total number of good moving spermatozoa per ejaculate.

\section{Discussion}

Those mammalian species possessing scrotal testes, including man, are sensitive to scrotal insulation which has been shown to disrupt spermatogenesis [1-3,17].

Our results suggest that occupational and living habits apparently through scrotal insulation can influence sperm quality. In particular the 'warm workers' and 'warm sleepers' had reduced numbers of good moving spermatozoa compared to the 'cool workers' and 'cool sleepers'.

Experimentally, damage to the testis can be produced by insulating the scrotum, so as to prevent normal heat loss or by heating the whole animal [3]. Repeated increase of body temperature, by means of excessive sauna use, was studied in man and it was shown to disrupt spermatogenesis [8]. Recently it has been shown that a fair assessment of testicular temperature could be achieved by scrotal temperature measurement [18]. Brindley reported effects of the type of underwear (Y-fronts vs. Boxer shorts) worn, common activities and posture on the deep scrotal temperature'. Men sitting with the legs crossed or sleeping with underwear have the highest deep scrotal temperatures [11]. Mieusset et al. observed significantly higher scrotal temperatures in infertile than in fertile men. Furthermore, in the infertile men it was found that the higher the scrotal temperature, the more altered the sperm characteristics [19]. 
Negative influence of occupation and living habits on semen quality have to be considered carefully by designing a treatment protocol for male infertility. Improved seminal characteristics in infertile men after a conservative treatment regimen based on the avoidance of testicular hyperthermia (due to hot baths and/or tight clothing) have already been reported [20]. Recently it has been shown that in 36 'hard core' infertility couples cooling of the scrotum resulted in a pregnancy in 11 out of 25 couples [17]. It has been demonstrated that after prolonged cooling of the scrotum sperm concentration and motility improved in oligospermic men [21].

Future research will concentrate on 24-hour monitoring of deep scrotal temperature and its relationship to intra-testicular temperature and male infertility.

\section{References}

1 Zorgniotti AW. Testis temperature, infertility and the varicocele paradox. Urology 1980;16:7-10.

2 Zorgniotti AW. Elevated intrascrotal temperature. 1. A hypothesis for poor semen in infertile men. Bull NY Acad Med 1982;58:535-540.

3 Setchell BP, Ed. Naturally occurring and induced dysfunction of the testis. In: The mammalian testis. London: Elek Books Limited, 1978;359-432.

4 Dahl EV, Herrick JF. A vascular mechanism for maintaining testicular temperature by counter-current exchange. Surg Gynecol Obstet 1959;108:697-705.

5 Hendry WF. Loose pants and cold scrotal douches: effects on spermatogenesis. Prog Reprod Biol $1976 ; 1: 259-262$.

6 Moore CR, Quick WMJ. The scrotum as a temperature regulator for the testes. Am J Phys 1924;68:70-79.

7 Waites GMH, Moule GR. Relation of vascular heat exchange to temperature regulation in the testis of the ram. J Reprod Fertil 1961;2:213-224.

8 Procope BJ. Effect of repeated increase of body temperature on human sperm cells. Intern $\mathbf{J}$ Fert 1965;10:333-339.

9 Galil KAA, Setchell BP. Effects of local heating of the testes on the concentration of testosterone in jugular and testicular venous blood of rats and on testosterone in vitro. Intern J Androl 1987;11:61-72.

10 Galil KAA, Setchell BP. Effects of local heating of the testis on testicular bloodflow and testosterone secretion in the rat. Intern J Androl 1987;11:73-85.

11 Brindley GS. Deep scrotal temperature and the effect on it of clothing, air temperature, activity, posture and paraplegia. Br J Urol 1982;54:49-55.

12 Alexander NJ. Male evalution and semen analysis. Clin Obstet Gynecol 1982;25:463-482.

13 Smith CG. Drug effects on male sexual function. Clin Obstet Gynecol 1982;25:525-531.

14 Netto NR Jr., Lemos GC, Babosa EM. The value of thermography and of Doppler ultrasound in varicocele diagnosis. Inter J Fertil 1984;29:176-179.

15 Belsey MA, Eliasson R, Gallegos AJ, et al., eds. Laboratory manual for the examination of human semen and semen cervical mucus interaction. World Health Organisation. Singapore: Press Concern, 1980.

16 Overstreet JW, Price MJ, Blazak WF, et al. Simultaneous assessment of human sperm motility and morphology by videomicrography. J Urol 1981;126:357-360.

17 Zorgniotti AW, Sealfon AI, Toth A. Chronic scrotal hypothermia as a treatment for poor semen quality. Lancet 1980;26:904-906.

18 Kurz KR, Goldstein M. Scrotal temperature reflects intratesticular temperature and is lowered by shaving. J Urol 1986;135:290-292.

19 Mieusset R, Bujan L, Mondinat C, et al. Association of scrotal hyperthermia with impaired spermatogenesis in infertile men. Fertil Steril 1987;48:1006-1011.

20 Lynch R, Lewis-Jones ID, Machin DG, et al. Improved seminal characteristics in infertile men after a conservative treatment regimen based on avoidance of testicular hyperthermia. Fertil Steril 1986;46:476-479.

21 Zorgniotti AW, Saelfon BSEE. Scrotal hypothermia: new therapy for poor semen. Urology 1984;23:439-441. 